\title{
Counter Current Flow Limitation of Gas-Liquid Two-Phase Flow in Nearly Horizontal Pipe
}

\author{
Sigit Prayitno, ${ }^{1}$ R. A. Santoso, ${ }^{1}$ Deendarlianto, ${ }^{1}$ Thomas Höhne, ${ }^{2}$ and Dirk Lucas ${ }^{2}$ \\ ${ }^{1}$ Department of Mechanical \& Indutrial Engineering, Faculty of Engineering, Gadjah Mada University, Jalan Grafika No. 2 \\ Yogyakarta 55281, Indonesia \\ ${ }^{2}$ Helmholtz Zentrum Dresden Rossendorf, Institute of Safety Research, P.O. Box 510 119, 01314 Dresden, Germany
}

Correspondence should be addressed to Deendarlianto, deendarlianto@ugm.ac.id

Received 13 December 2011; Accepted 29 February 2012

Academic Editor: Michio Murase

Copyright () 2012 Sigit Prayitno et al. This is an open access article distributed under the Creative Commons Attribution License, which permits unrestricted use, distribution, and reproduction in any medium, provided the original work is properly cited.

\begin{abstract}
Experimental work about counter current two-phase flow of air and gas in nearly horizontal pipe has been performed. The work was performed in a $1.1 \mathrm{~m}$ long circular transparent acrylic pipe with $50 \mathrm{~mm}$ inner diameter, in two inclination angle settings $\left(20^{\circ}\right.$ and $10^{\circ}$ from horizontal). The smooth liquid and air inlet was used. Porous liquid inlet and a nozzle connected with calm section were used as liquid and gas inlet. The effect of liquid properties is examined by using five different working fluids (Water, two different concentration of butanol and glycerin aqua solutions). As for results. (1) CCFL causes a drastic change in the delivered liquid to the lower plenum. (2) The effect of inclination angle is significantly observed. The flooding gas superficial velocity decreases with inclination angle. (3) The liquid viscosity affects the flooding phenomena.
\end{abstract}

\section{Introduction}

Counter current flow in vertical tube has many applications in a diverse range of process industries. The phenomenon of flooding is of considerable technological importance, as flooding can be limiting factor in the operation of equipment. For example, in a pressurized water reactor (PWR), the counter-current flow of steam (upward) and cold water (downward) may take place in vertical channels when the emergency core cooling (ECC) water is injected into the reactor vessel. This leads to complex processes including the condensation of steam due to the introduction of cold water in to the reactor core. Most importantly upward steam flow may prevent sufficient cooling of reactor component by ECC water. Flooding phenomena have been studied in order to develop analytical models to predict the onset of flooding velocity. As a result, a large number of correlations have been proposed in the literature to predict it for given set of condition. In spite of the large number of reported results, there is still considerable uncertainty concerning the phenomena at the onset of flooding.

A previous work by Wallis [1] who studied counter current of liquid-gas flow in vertically channel found the inversely proportional relationship of the liquid and gas velocity. To provide a further observation, Hewitt [2] and Barnea et al. [3] performed an experiment in inclined pipe and showed the effect of inclination angle. They found that the effect of inclination angle is complicated. The flow rate at which flooding occurs increases and then decreases as the inclination angle is changed from horizontal to vertical. In the other hand, Pantzali et al. [4] showed the tendency of the flooding gas flow rate increase with the increase of the inclination angle.

Another important aspect in flooding is the influence of the liquid properties. Kamei et al. [5] performed an experimental work about the effect of surface tension in flooding phenomena. They concluded that the flooding gas 2velocity increases with the decrease of surface tension. A further experimental work performed by Suzuki et al. [6] conclude that the effect of surface tension is complicated. The opposite result was showed by Ousaka et al. [7], Chung et al. [8], and Zapke and kröger [9]. They showed that surface tension had a stabilizing effect on flooding. It is proved by the instability of interfacial area and the decrease of flooding velocity with the decrease of surface tension. An experimental work about the effect of liquid viscosity was performed by Clift et al. [10], 


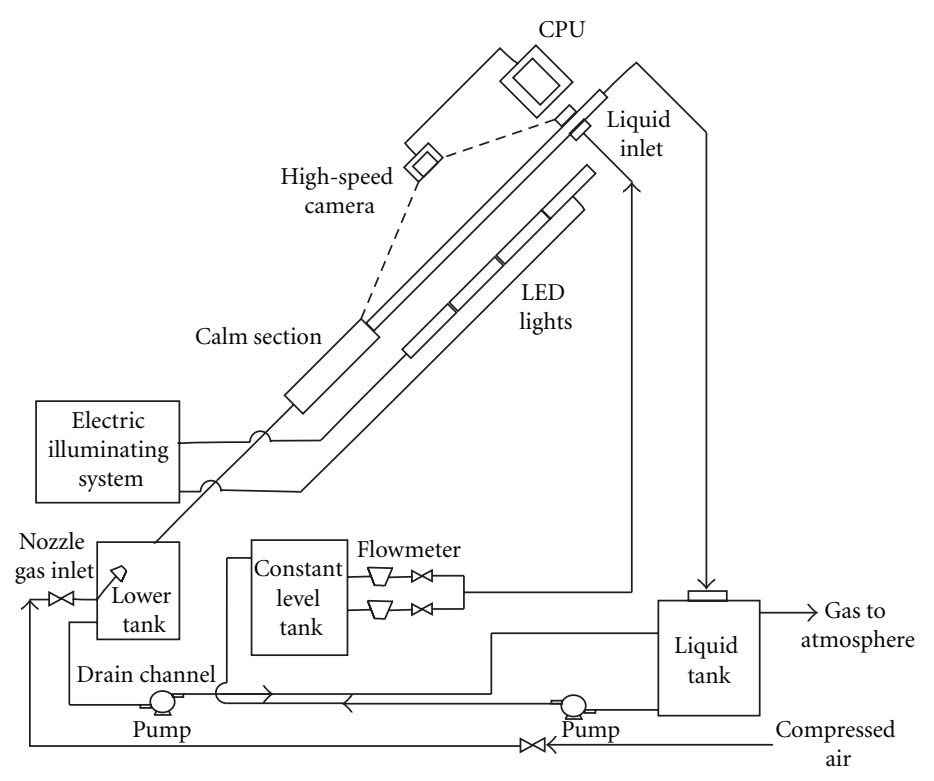

FIgURE 1: The schematic of experimental apparatus.

they found the destabilizing effect of viscosity, an increase of viscosity is followed with the decrease of flooding velocity. This result is fully in agreement with Tien et al. [11], Chung et al. [8], Zapke and kröger [9], Mouza et al. [12], and Nariai et al. [13]. Suzuki et al. [6] found the opposite trend. They found that the flooding velocity tend to increase with an increase in liquid viscosity.

The previous experimental works revealed that the agreement has not been met. The main objective of the work described in the present experimental work is to examine the influence of the fluid properties and the pipe inclination on the CCFL. Air, water, and two different butanol and glycerin aqua solutions were used as the working fluid for this purpose. The two inclination angles, $20^{\circ}$ and $10^{\circ}$ from horizontal axis are used to provide more observation data that is very limited in the low-inclination angle.

\section{Experimental Apparatus}

A scheme of this present experimental facility is shown in Figure 1. The tests were performed in a $1.1 \mathrm{~m}$ long circular transparent acrylic pipe with $50 \mathrm{~mm}$ inner diameter. The transparent circular acrylic test section was mounted in the aluminium beam, which designed to be able to be assembled in two inclination angles: 20 and 10 degree from horizontal axis. Compressed air was supplied by a reservoir, and the flow gas was regulated by the digital regulator. Air entered via nozzle connected to the lower plenum and calm section to provide a smoother air flow rate entering the test section. The air flows from the larger to the small section area of the calm section to minimize the disturbance effect in the air streamline. This method was used in the previous work done by Deendarlianto et al. [14]. The liquid was supplied by the feeder pump connected to the liquid tank. The liquid supply flow rate and temperature were measured with signet flow transmitter and the digital thermometer to assure the liquid supplied as the experimenter expected. The detail of the air inlet and calm section geometry are shown in Figures 2 and 3. The porous liquid entry was used as the smooth liquid entry as shown in Figure 4.

The present experiments were performed using air and five test liquids, that is water, two difference concentration of butanol and glycerin aqua solutions, thus providing test liquid with a variation of surface tension $\sigma$ and viscosity $\mu$. The liquid properties were measured in the ambient temperature condition, that is, $\pm 22^{\circ} \mathrm{C}$ and their properties are given in Table 1. The sample of the liquid tests is taken during the experiment and compared to the data sheet of liquid properties of the mixtures. A good agreement was resulted, the mixtures were under soluble condition and met the liquid properties data sheet.

The onset of flooding was detected as follows, that is, by stepwise increase with a small increment of air-flow rate under a constant water flow rate. Firstly we waited for a few minutes to ensure the flow pattern was in a steady state after the change of the air flow rate. At the same time, a visual data observation and the delivered liquid flow rate were recorded. The onset of flooding was defined as the limiting point of stability of the counter-current flow, indicated by the maximum air flow rate at which the delivered liquid flow rate was equal to the inlet liquid flow rate. As the air flow rate was increased continuously, a flow pattern transition occurs. The stable counter current flow tended to be unstable. The unstable counter current flow was indicated at which the difference of the liquid flow rate from upper plenum to the delivered liquid flow rate in the lower plenum was found. The delivered liquid flow rate in the lower plenum decreases with an increase in the air flow rate. This condition is called as counter current flow limitation (CCFL) or flooding. This 


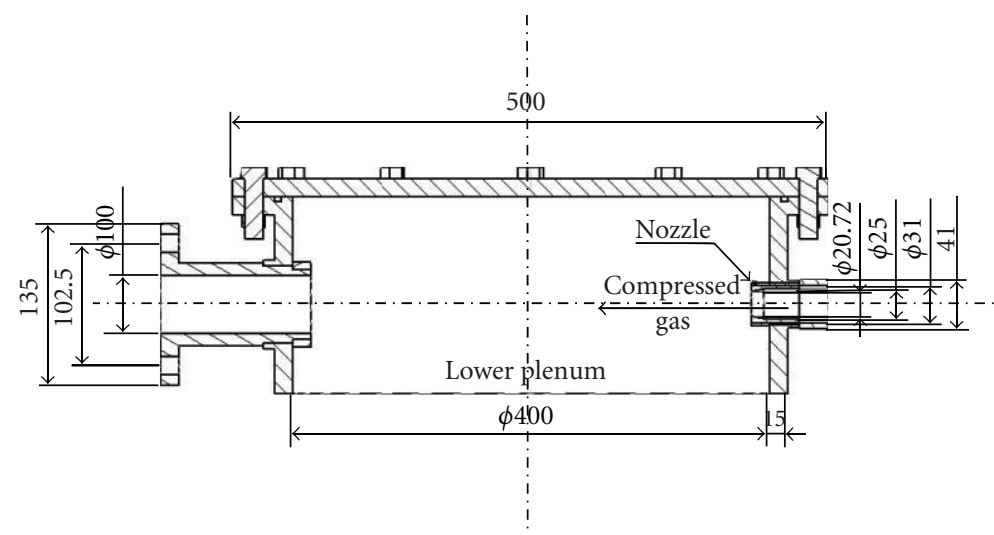

FIgURe 2: Nozzle air inlet.

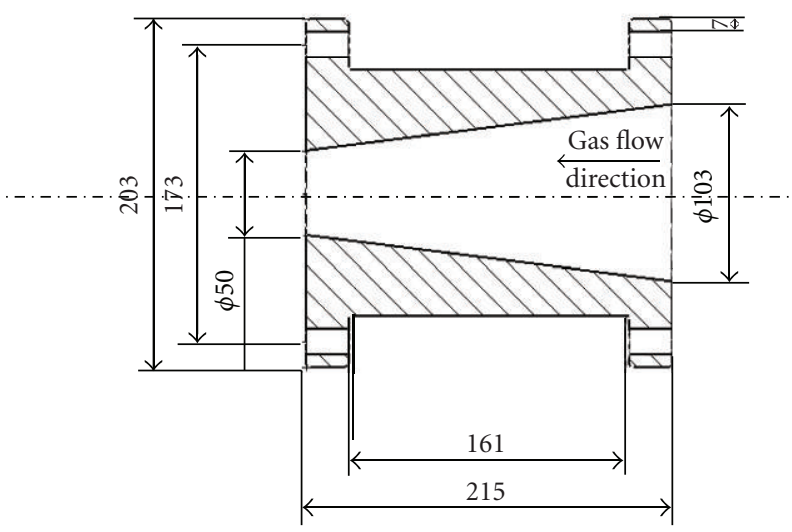

Figure 3: Calm section.

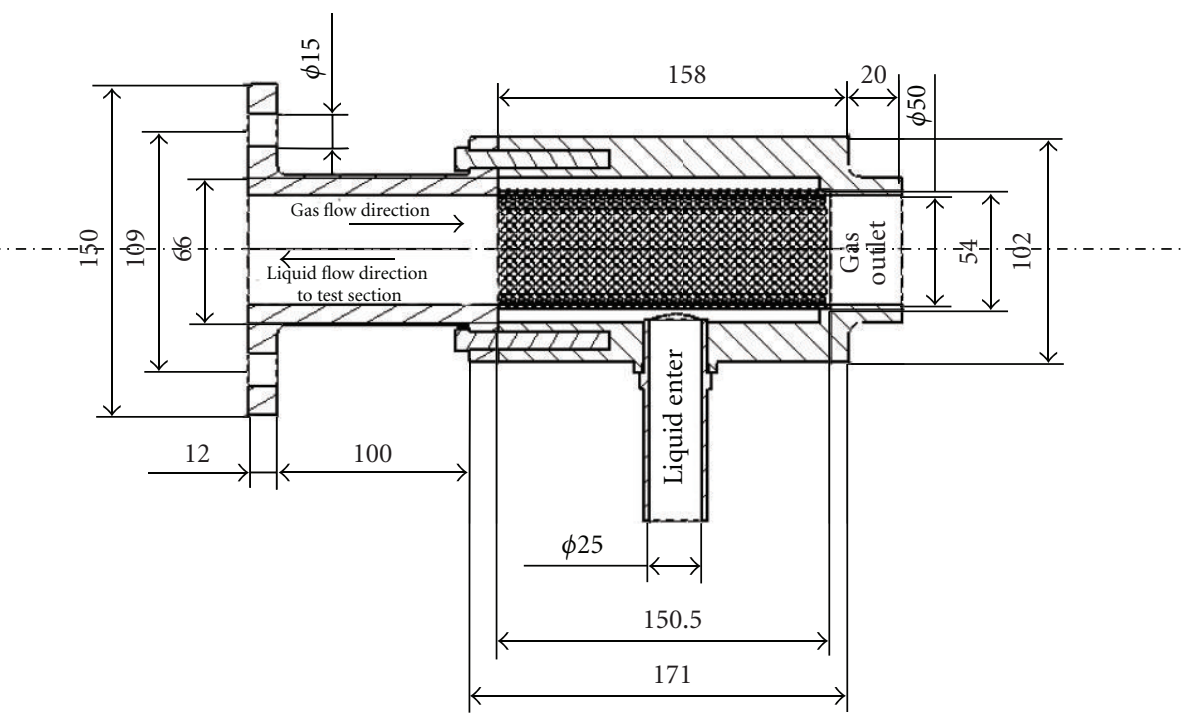

FIgURE 4: Porous liquid inlet. 
TABLE 1: Liquid properties*.

\begin{tabular}{|c|c|c|c|c|}
\hline Fluid & Density $\left[\mathrm{kg} / \mathrm{m}^{3}\right]$ & Surface tension $[\mathrm{mN} / \mathrm{m}]$ & Viscosity [mPa.s] & Index \\
\hline Water & 997.00 & 73.62 & 1.002 & $\mathrm{~W} 1$ \\
\hline $30 \%$ glycerin aqua solution & 1064.25 & 69.49 & 2.633 & V1 \\
\hline $50 \%$ glycerin aqua solution & 1104.6 & 69.34 & 5.164 & V2 \\
\hline $2 \%$ butanol aqua solution & 994 & 51.45 & 1.245 & S1 \\
\hline $5 \%$ butanol aqua solution & 989.5 & 39.76 & 1.266 & S2 \\
\hline
\end{tabular}

${ }^{*}$ The measured fluid properties were measured in the ambient condition $\left(P=101325 \mathrm{~N} / \mathrm{m}^{2}, \mathrm{~T}=295^{\circ} \mathrm{K}\right)$.

method was used by the previous investigators such as Celata et al. [15] and Deendarlianto et al. [14].

The superficial velocity is described as the ratio between flow rate and crosssection of the circular channel as shown below:

$$
J_{k}=\frac{Q}{A_{s}}
$$

at which subscript $k$ indicates $G$ supplied gas and $L, d$ delivered liquid phase, $J$ superficial velocity, $Q$ flowrate, and $A_{s}$ inner crosssection area of the circular acrylic pipe.

The experimental conditions were conducted in the range of supplied liquid superficial velocity $J_{L}=0.023 \sim$ $0.24 \mathrm{~m} / \mathrm{s}$ and that of air $J_{G}=0 \sim 13.8 \mathrm{~m} / \mathrm{s}$.

\section{Results and Discussion}

To simplify the explanation in this paper, we use some abbreviations for the test liquids by referring to their liquid properties. The significance of abbreviations described in this paper is as follows: W1: air-water $(\sigma=0.073 \mathrm{~N} / \mathrm{m}$ and $\boldsymbol{\mu}=0.001 \mathrm{~Pa} . \mathrm{s}), \mathrm{S} 1: 2 \%$ butanol aqua solution $(\boldsymbol{\sigma}=0.051$ $\mathrm{N} / \mathrm{m}), \mathrm{S} 2: 5 \%$ butanol aqua solution $(\boldsymbol{\sigma}=0.039 \mathrm{~N} / \mathrm{m}), \mathrm{V} 1$ $30 \%$ glycerin aqua solution ( $\boldsymbol{\mu}=0.0026$ Pa.s $)$ and V2 50\% glycerin aqua solution $(\boldsymbol{\mu}=0.0051 \mathrm{~Pa} . \mathrm{s})$.

Figure 5 illustrates the effect of pipe inclination angle on the CCFL in terms of the gas superficial velocities $J_{G}$ and the delivered liquid superficial velocities $J_{L, d}$. The effect of inclination angle was found in the range of $J_{L, d} \leq 0.15 \mathrm{~m} / \mathrm{s}$ at which flooding occurs in the pipe section. The flooding gas superficial velocities observed tend to decrease in the decrease of the pipe inclination angle. It might be as the effect of gravitational forces. The decrease of the inclination angle dilutes the gravity force, it means that the role of gravity force to counteract the air flow rate becomes weaker in the decrease of inclination angle, therefore, the air flow rates needed to make an upward liquid flow decrease in the decrease of inclination angle. It causes the slope of the plotted $20^{\circ} \mathrm{CCFL}$ curve to be higher than $10^{\circ} \mathrm{CCFL}$ curve as shown in Figure 5. Figures 5(a), 5(b), 5(c), and 5(d) show that the effect of inclination angle is getting weaker at high delivered liquid superficial velocities. It is proved by the two plotted curves that are closer to each other. It may be considered as the effect of an irregular wave formed in the liquid inlet area and tends to block the crosssection. This indicates the occurrence of the entrance flooding.

In order to observe the behavior of the liquid film on the CCFL condition, visual observation was performed by the Redlake Motion Pro high-speed video camera. Bundled with $500 \mathrm{fps}$ and $1280 \times 1024$ as the maximum framerate and resolution, it can assure the good quality of visual observation data. The camera is set up in the 200 frames per second to provide a good visual observation data as shown in Figures 6, 7, and 8. A tendency is observed, the liquid film flows like a wavy appears at the onset of flooding, then the waves increase in the height. As the wave height reaches a certain value, the wave begins to be broken up by the air flow. There is some droplet entrainment in air flow rate. The three liquid tests show the same trend, but it is not fully the same. The different phenomena are shown by the three liquid tests (W1, S2, and V2). V2 shows the higher height and frequency of the wave formed, compared to W1 in the same of time range. S2 shows that the droplet entrainment occurs in the smaller wave compared to $\mathrm{W} 1$, it means that the height of the wave needed to be broken is smaller than other. These indicate that CCFL characteristic depends on the liquid properties.

Wallis [1] proposed the dimensionless number or known as Wallis parameter, $J_{k}{ }^{*}$, in terms of the dimensionless gas and liquid superficial velocities to predict the onset of flooding in vertical pipe. It is defined as follows:

$$
J_{k}{ }^{*}=J_{k} \sqrt{\frac{\rho_{k}}{g D\left(\rho_{l}-\rho_{g}\right)}},
$$

at which subscript $k$ indicates $G$ gas and $L, d$ delivered liquid phase, $\rho$ the density, and $D$ is the inner diameter of the pipe used. The correlation is expressed as,

$$
J_{G}{ }^{1 / 2}+m J_{L, d}{ }^{1 / 2}=C,
$$

the constants $m$ and $C$ are based on the experiment set up and condition.

Figure 9 illustrates the effect of surface tension on the CCFL in terms of the dimensionless number as proposed by Wallis in which (a) and (b) correspond to the cases of W1, $\mathrm{S} 1, \mathrm{~S} 2$, in the 20 and 10 degree inclination angle. The close observation of the figure reveals that the effect surface tension on CCFL is not significantly observed. The destabilizing effect of surface tension was only observed in the liquid film behavior as shown in Figure 8. The very chaotic flow pattern was shown. It can be explained as the decrease of surface tension means a smaller pressure difference in the liquid-gas interfacial area can be restrained by the liquid film. It causes the liquid behavior to be unstable flow easily. Therefore, the more chaotic flow is performed and the droplet entrainment 


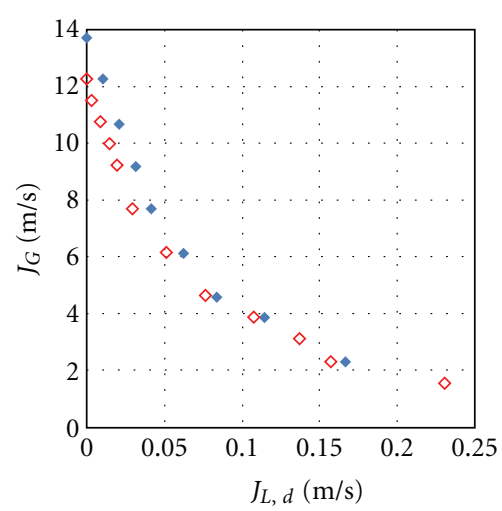

W1

$\checkmark 20^{\circ}$

$\diamond 10^{\circ}$

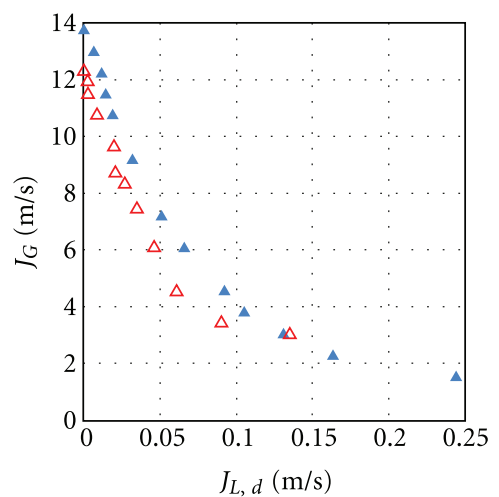

V1

\ $20^{\circ}$

$\triangle 10^{\circ}$

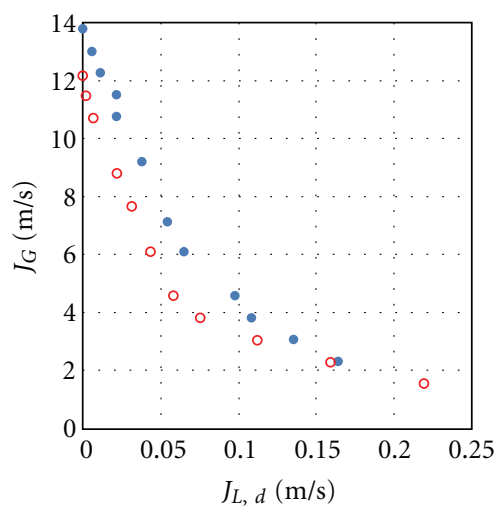

V2

- $20^{\circ}$

$\circ 10^{\circ}$

(a) $\mathrm{W} 1$

(b) V1

(c) V2

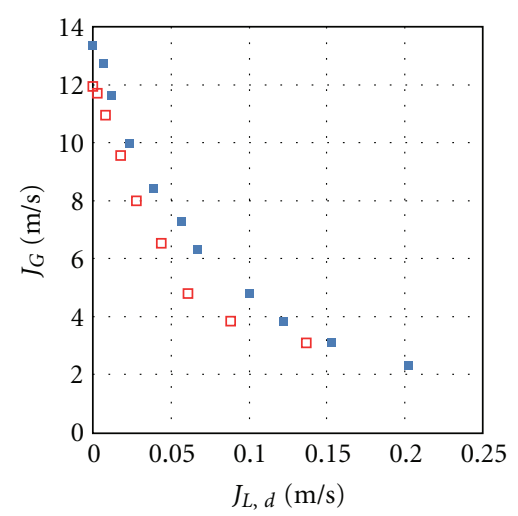

S1

- $20^{\circ}$

$\square 10^{\circ}$

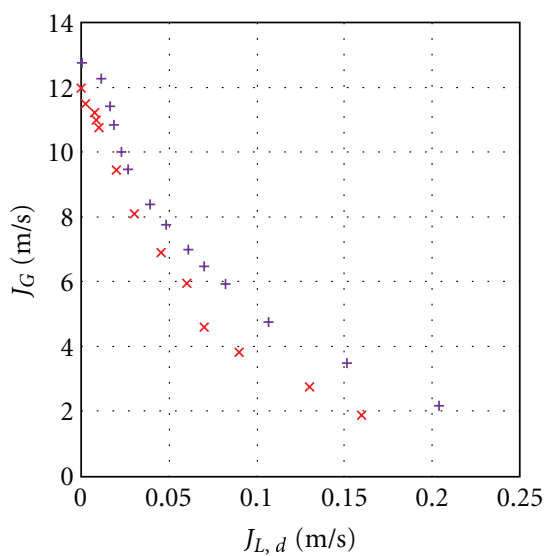

S2

$+20^{\circ}$
$\times \quad 10^{\circ}$

(d) S1

(e) S2

FIgURE 5: Effect of pipe inclination angle in the flooding.

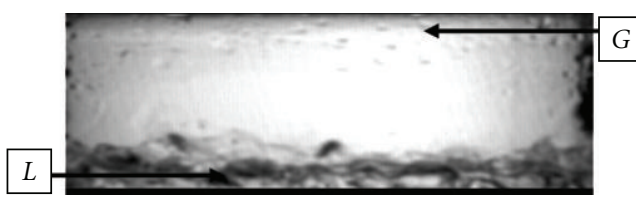

(a) $t=7 \mathrm{~s}$

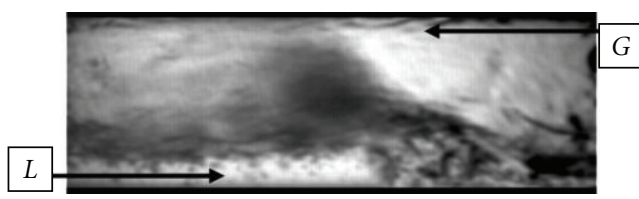

(c) $t=8.9 \mathrm{~s}$

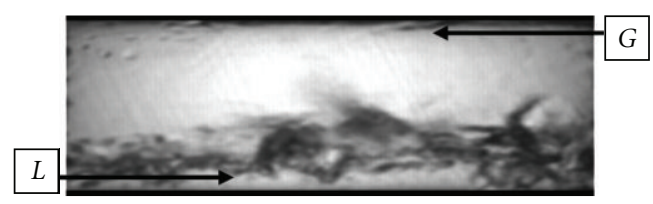

(b) $t=7.3 \mathrm{~s}$

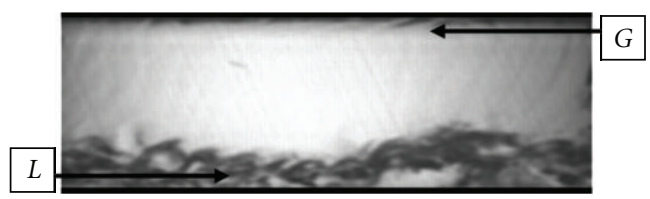

(d) $t=9.4 \mathrm{~s}$

Figure 6: A typical sequence of frames showing the liquid film behavior on CCFL condition of W1 $\left(J_{L, d}=0.0019 \mathrm{~m} / \mathrm{s}, J_{G}=9.2 \mathrm{~m} / \mathrm{s}\right.$ and $\left.\theta=10^{\circ}\right)$. 


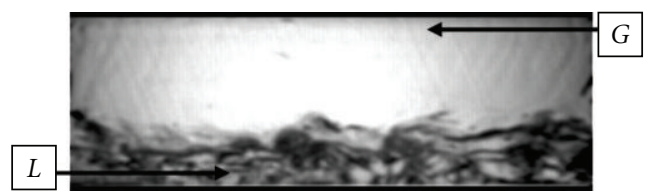

(a) $t=1.9 \mathrm{~s}$

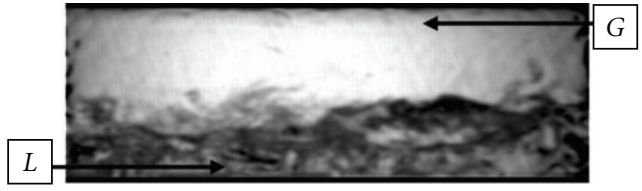

(c) $t=5.9 \mathrm{~s}$

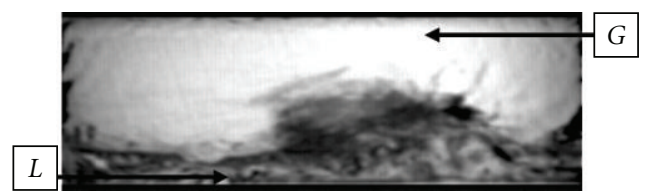

(b) $t=3.8 \mathrm{~s}$

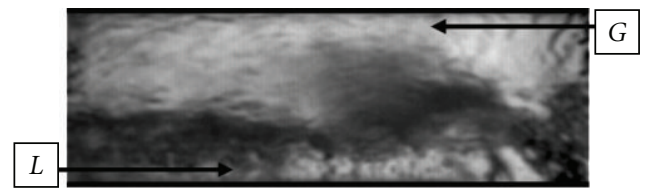

(d) $t=9.4 \mathrm{~s}$

FIGURE 7: A typical sequence of frames showing the liquid film behavior on CCFL condition of V2 $\left(J_{L, d}=0.0018 \mathrm{~m} / \mathrm{s}, J_{G}=9.19 \mathrm{~m} / \mathrm{s}\right.$ and $\theta=$ 10.

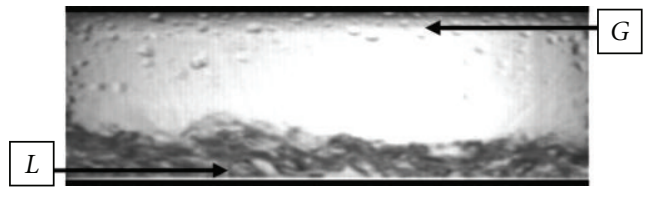

(a) $t=0.13 \mathrm{~s}$

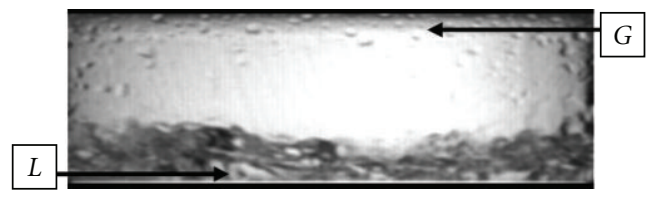

(c) $t=2.4 \mathrm{~s}$

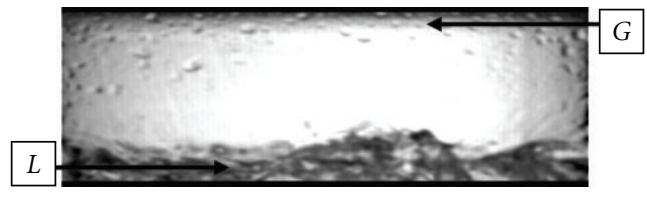

(b) $t=0.56 \mathrm{~s}$

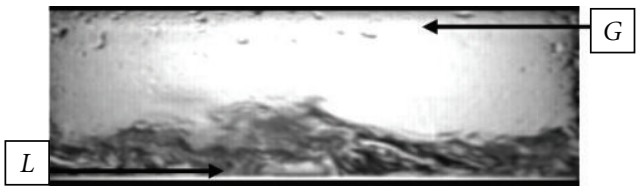

(d) $t=4.2 \mathrm{~s}$

FIGURE 8: A typical sequence of frames showing the liquid film behavior on CCFL condition of S2 $\left(J_{L, d}=0.0084 \mathrm{~m} / \mathrm{s}, J_{G}=10.8047 \mathrm{~m} / \mathrm{s}\right.$ and $\theta$ $=10^{\circ}$.
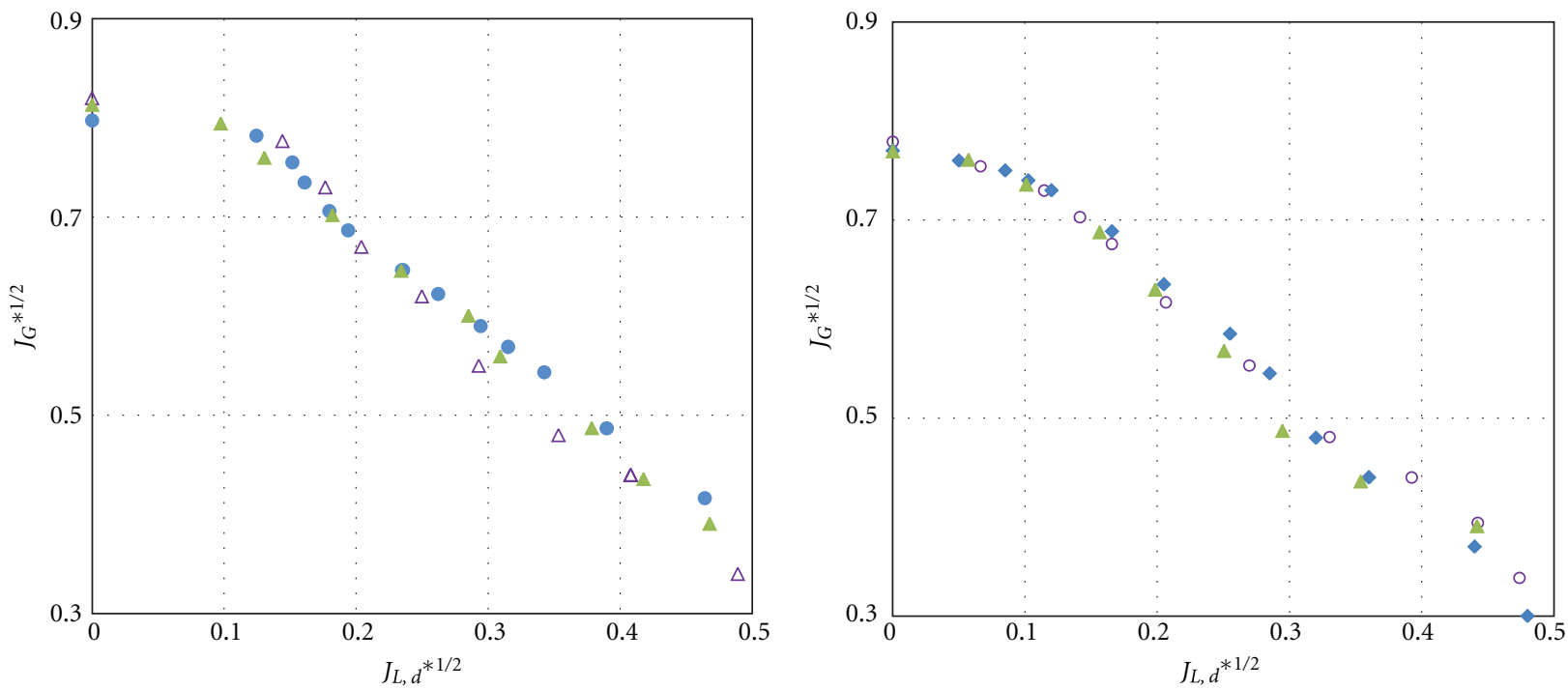

$$
\begin{aligned}
& \theta=20^{\circ} \\
& \Delta \mathrm{W} 1 \\
& \\
& \Delta \mathrm{S} 1 \\
&-\mathrm{S} 2
\end{aligned}
$$$$
\theta=10^{\circ}
$$$$
\triangle \mathrm{W} 1
$$$$
\Delta \mathrm{S} 1
$$$$
\text { - S2 }
$$
(a) $20^{\circ}$
(b) $10^{\circ}$

Figure 9: The effect of liquid surface tension on the flooding. 


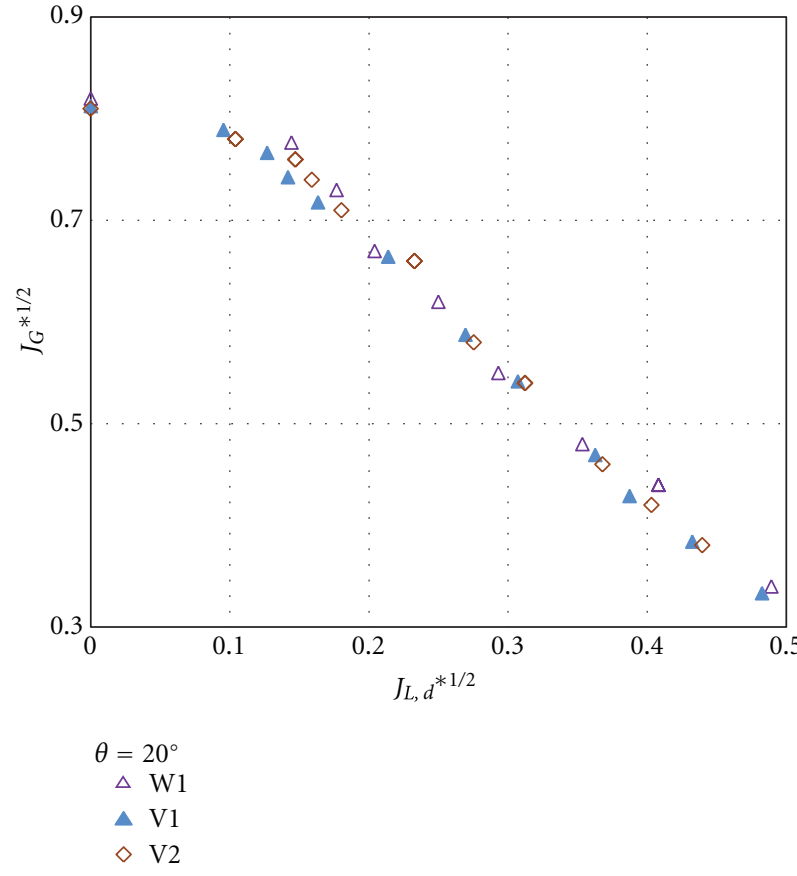

(a) $20^{\circ}$

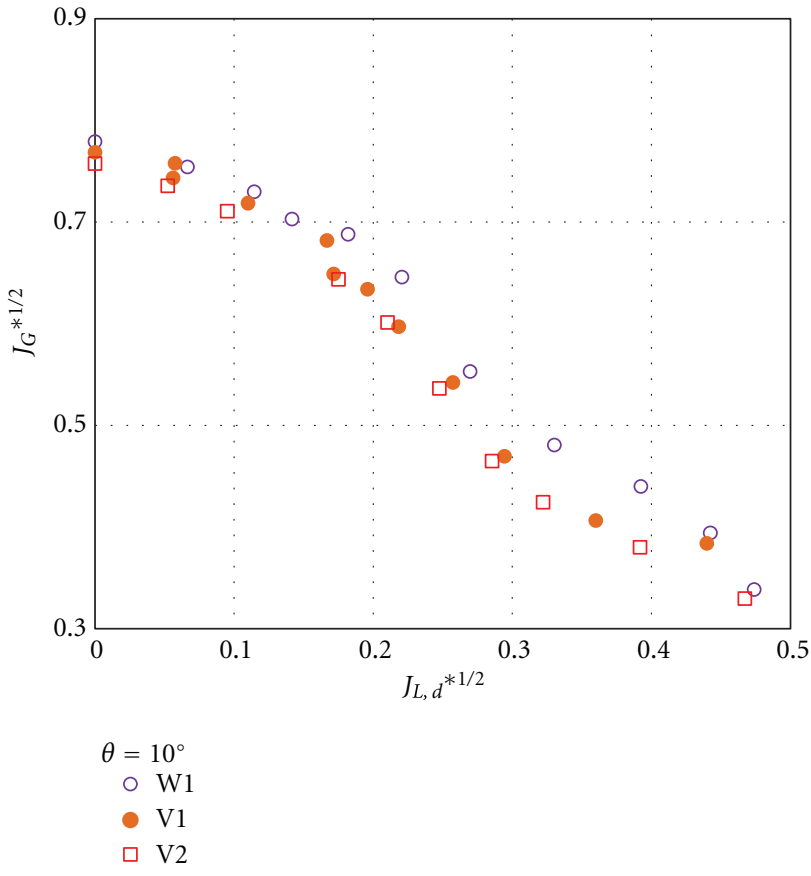

(b) $10^{\circ}$

FIGURE 10: The effect of the liquid viscosity on flooding.

occurs in the smaller wave height. It is very interesting that the observed chaotic flow pattern does not significantly affect the plotted gas flooding superficial velocities. It is proved by the plotted CCFL curve that perform close to each other as shown in Figure 9. This result is in fully agreement with Nariai et al. [13] who performed the CCFL experiment in the same inner diameter pipe used in this present work. The Figures 9(a) and 9(b) show the different slope of the two plotted inclination angle experiment data. The curve slope of Figure 9(a) is higher than 9(b), it is considered as the slope " $m$ " in Wallis correlation closely related to geometrical dimension. The geometrical dimension here is inclination angle. The inclination angle corresponds to the gravity force that dominantly influences the CCFL in both of plotted W1, $\mathrm{S} 1$ and S2 curves.

Further observation was done to examine the effect of the viscosity on flooding. Figure 10 shows CCFL data plotted in terms of dimensionless number proposed by Wallis. An increase in the liquid viscosity means an increase in the flow resistance. As the liquid flows down, the liquid film pressure reduces due to the effect of friction, hence the pressure different in the liquid-gas interface area increases. A fluctuated wave is formed to compensate the additional pressure different in the liquid-gas interface area. Figure 10(a) shows that the CCFL curves of W1, V1 and V2 are close to each other. It means that the fluctuated wave does not always correspond to the destabilizing effect, there is stabilizing mechanism that is able to delay the destabilizing effect. Chung et al. [8] proposed a new viscous effect, that is, viscous damping effect which was not accounted before. Viscous damping as the ability of the liquid to stabilize the flow behavior will counteract with the destabilizing effect of viscosity, therefore, the net liquid viscosity effect is found to be very small. The different condition is illustrated by Figure 10(b), an increase in the viscosity causes the decrease of the gas superficial velocity. It is considered as the destabilizing effect of viscosity. The destabilizing effect of viscosity appears dominantly to the viscous dumping. It is proved by the high-frequency wave formed as shown in the Figure 7. It may be caused by the effect of inclination angle that dilutes the gravity forces that correspond to the viscous damping effect. Therefore, the CCFL curves of V1 and V2 tend to lag behind the W1.

A comparison is made to know the tendency of the flooding experimental works in inclined pipe. The comparison in the inclined pipe is made by plotting the data in the dimensionless number as shown in Figure 11.

Figure 11(a) shows a comparison of the present experimental data with the data resulted by Barnea et al. [3] and Geweke et al. [16]. Although this present work used the same inner diameter pipe as Barnea et al. [3] and Geweke et al. [16], the comparison indicates that there is a different condition observed in these experiments. The Barnea et al. data shows the highest $J_{G}{ }^{* 1 / 2}$ than others. It may be caused by the 10 meters long pipe and the difference of the definition of the flooding used. Geweke et al. [16] data shows the closely agreement with the present, it performs a slightly higher plotting. It may be due to the higher pressure of the system used than the present work used. As we knows from the literature that the higher pressure system condition tends to increase the flooding velocities, it is considered as the effect of the fluid properties used, change with the function of pressure, and temperature condition. 


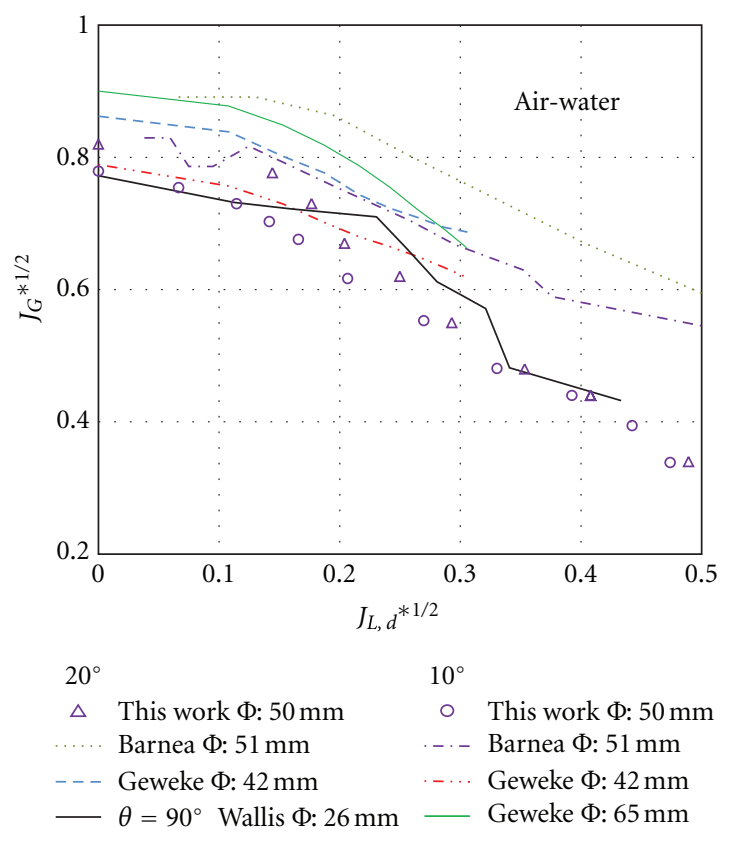

(a) The comparison of air-water experimental data

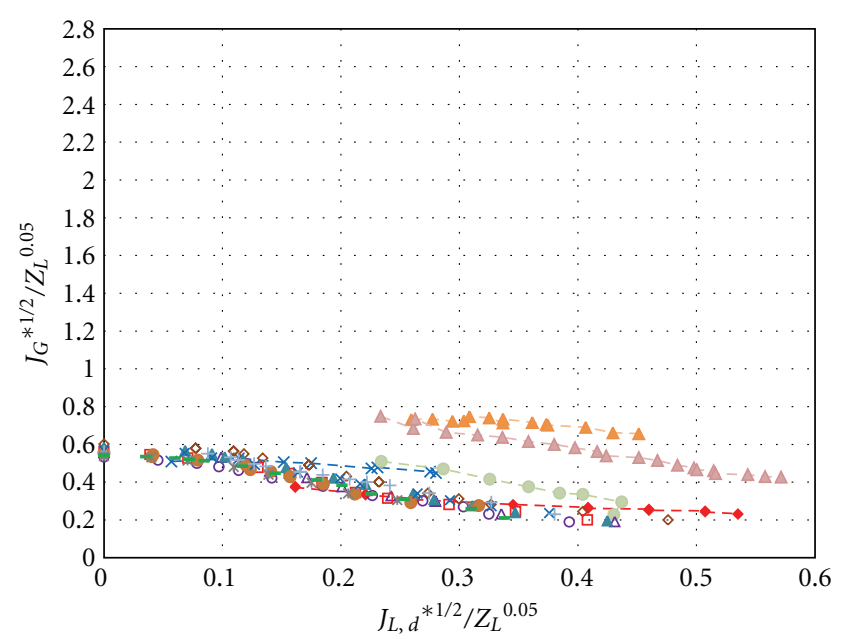

$\begin{array}{cc}20^{\circ} & \text { This work } \\ \Delta & \text { W1 } \\ \Delta & \text { V1 } \\ \diamond & \text { V2 } \\ \times & \text { S1 } \\ + & \text { S2 }\end{array}$

$\begin{array}{cc}10^{\circ} & \text { This work } \\ \circ & \mathrm{W} 1 \\ - & \mathrm{V} 1 \\ \square & \mathrm{V} 2 \\ * & \mathrm{~S} 1 \\ & \mathrm{~S} 2\end{array}$

Chung et al. $\Phi: 31 \mathrm{~mm} \theta: 90^{\circ}$

- oil 3

Clift et al. $\Phi: 31 \mathrm{~mm} \theta: 90^{\circ}$

$-\star-59 \%$ Gly.Aq.Sol.

Pantzali et al. Ф: $9 \mathrm{~mm} \theta: 30^{\circ}$

- 4 - 50\% Gly.Aq.Sol

$\triangle \quad 2 \%$ But.Aq.Sol.

Ousaka et al. $\Phi: 16 \mathrm{~mm} \theta: 45^{\circ}$

- -0.02 WT \% oleic acid natrium sol.

(b) The comparison of air-various liquid experimental data

FIGURE 11: The data comparison of flooding experimental data.

An increase in the pipe inclination angle, the experimental data resulted by Wallis [1] show a slight lower CCFL curve. It may due to the difference diameter used in his vertical pipe flooding experiment.

Zapke and Kröger [9] examined the countercurrent gas-liquid flow in inclined tubes. They noted that the flooding is significantly affected by the liquid properties. They claim that the constant $C$ in the Wallis correlation is a function of the liquid properties. Then, they proposed a dimensionless liquid property parameter to be combined to Wallis correlation to provide a trend of flooding phenomena. It was proved successfully to correlate some experimental data. The liquid property parameter is defined as follows:

$$
Z_{L}=\frac{\sqrt{D \rho_{L} \sigma}}{\mu_{L}}
$$

A further comparison is made to evaluate the combination of Wallis dimensionless number $J_{k}{ }^{*}$ and Zapke dimensionless liquid property $Z_{L}$ to correlate the flooding experimental data. The comparison is made by the combination of
$J_{k}{ }^{* 0.5} / Z_{L}{ }^{0.05}$ to be the axis of the plotted data. This combination was proved as good enough correlation number by Zapke and Kröger [9]. It was proved by the good correlation of some experimental work data that concern in examining the effect of liquid properties.

As shown in Figure 11(b) it is shown that the combination of Wallis and the liquid property does not fully correlate the data. The data scatter widely, especially for an extremely change of geometrical dimension like inner diameter and inclination angle as shown in Ousaka et al. [7] and Pantzali et al. [4] plotted data. A new parameter is needed to be found to provide a general flooding correlation.

\section{Conclusion}

The onset of flooding in nearly horizontal pipe was investigated experimentally. The tube diameter and tube length were $50 \mathrm{~mm}$ an $1.1 \mathrm{~m}$, respectively. The experiments were carried out using water, two different concentrations of butanol aqua solution and glycerin aqua solution as test liquids. The results are summarized as follows. 
(1) The flooding is characterized by the inversely proportional relation of the flooding velocities that is, the flooding gas superficial velocities decrease with an increase in the liquid flow rate.

(2) The effect of inclination angle is significantly observed to affect the flooding phenomena. A decrease of the flooding gas superficial velocities is observed with the decrease of inclination angle.

(3) The liquid viscosity influence in the flooding phenomena is relatively stronger than the surface tension effect. It is proved by the destabilizing effect of viscosity that is strong enough to decrease the flooding gas superficial velocities.

(4) The viscous dumping effect is found as the minor effect of the liquid viscosity. This effect becomes stronger in a little change of the liquid viscosity, but the destabilizing effect of liquid viscosity is to be dominant in the decrease of inclination angle.

\section{Acknowledgments}

The author would like to thanks Dr. Deendarlianto for the knowledge, assistance, and patience in the performance of the experiment and the Helmholtz Zentrum Dresden Rossendorf Topflow Facility crews for their contribution in this experiment. This work is also partly supported by Alexander Van Humboldt Foundation in Germany.

\section{References}

[1] G. B. Wallis, One-Dimensional Two-Phase Flow, chapter 11, McGraw Hill, NewYork, NY, USA, 1969.

[2] G. F. Hewitt, "Influence of end conditions, tube inclination and physical properties on flooding in gas liquid flows," Harwell Report HTFS-RS 222, 1977.

[3] D. Barnea, N. Ben Yoseph, and Y. Taitel, "Flooding in inclined pipes: effect of entrance section," Canadian Journal of Chemical Engineering, vol. 64, no. 2, pp. 177-184, 1986.

[4] M. A. Pantzali, A. A. Mouza, and S. V. Paras, "Study of hydrodynamic characteristics of the liquid layer during countercurrent flow in inclined small diameter tubes: the effect of liquid properties," in Proceedings of the 6th International Conference on Multiphase Flow (ICMF'07), Leipzig, Germany, 2007.

[5] S. Kamei, J. Onishi, and T. Okane, "Flooding in a wetted wall tower," Chemical Engineering, vol. 18, pp. 364-368, 1954.

[6] S. Suzuki and T. Ueda, "Behaviour of liquid films and flooding in counter-current two-phase flow-part 1. flow in circular tubes," International Journal of Multiphase Flow, vol. 3, no. 6, pp. 517-532, 1977.

[7] A. Ousaka, Deendarlianto, A. Kariyasaki, and T. Fukano, "Prediction of flooding gas velocity in gas-liquid countercurrent two-phase flow in inclined pipes," Nuclear Engineering and Design, vol. 236, no. 12, pp. 1282-1292, 2005.

[8] K. S. Chung, C. P. Liu, and C. L. Tien, "Flooding in twophase countercurrent flows-II: experimental investigation," Physicochemical Hydrodynamics, vol. 1, pp. 209-220, 1980.

[9] A. Zapke and D. G. Kröger, "The influence of fluid properties and inlet geometry on flooding in vertical and inclined tubes,"
International Journal of Multiphase Flow, vol. 22, no. 3, pp. 461-472, 1996.

[10] R. Clift, C. L. Pritchard, and R. M. Nedderman, "The effect of viscosity on the flooding conditions in wetted wall columns," Chemical Engineering Science, vol. 21, no. 1, pp. 87-95, 1966.

[11] C. L. Tien and C. P. Liu, "Survey on vertical two phase countercurrent flooding," EPRINP-984, 1979.

[12] A. A. Mouza, S. V. Paras, and A. J. Karabelas, "Incipient flooding in inclined tubes of small diameter," International Journal of Multiphase Flow, vol. 29, no. 9, pp. 1395-1412, 2003.

[13] T. Nariai, A. Tomiyama, C. Vallée, D. Lucas, I. Kinoshita, and M. Murase, "Counter-current flow limitation in a scaled-down model of a PWR hot leg," in Proceedings of the International Topical Meeting on Nuclear Thermal-Hydraulics, Operation and Safety (NUTHOS-8) N8P0109, pp. 10-14, Shanghai, China, 2010.

[14] Deendarlianto, A. Ousaka, A. Kariyasaki, T. Fukano, and M. Konishi, "The effects of surface tension on the flow pattern and counter-current flow limitation (CCFL) in gas-liquid twophase flow in an inclined pipe," Japanese Journal of Multiphase Flow, vol. 18, pp. 337-350, 2004.

[15] G. P. Celata, M. Cumo, and T. Setaro, "A data set of flooding in circular tubes," Experimental Thermal and Fluid Science, vol. 5, no. 4, pp. 437-447, 1992.

[16] H. Beckmann and D. Mewes, "Experimental studies of countercurrent flow in inclined tubes," in Proceedings of the European Two Phase Flow Group Meeting, p. B1, Rome, Italy, 1991. 

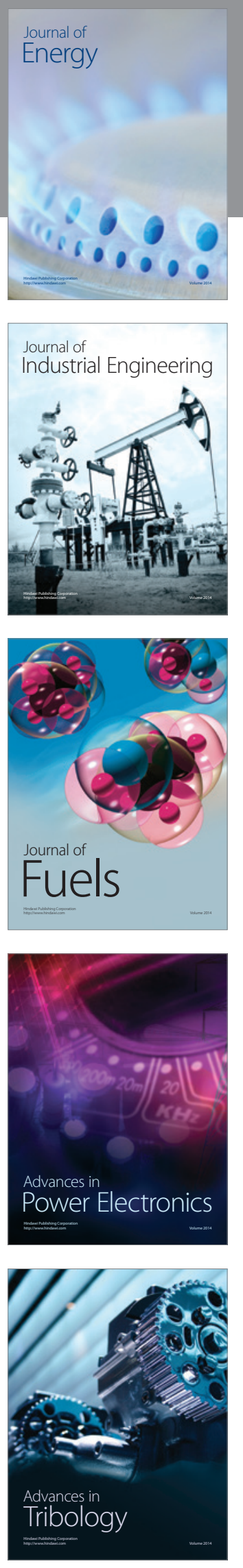
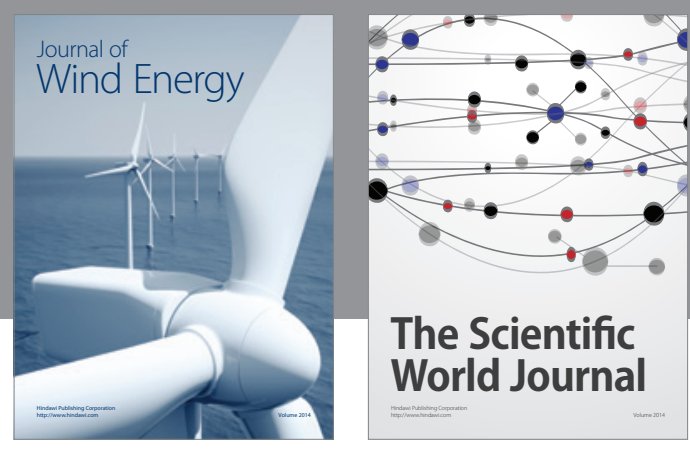

The Scientific World Journal

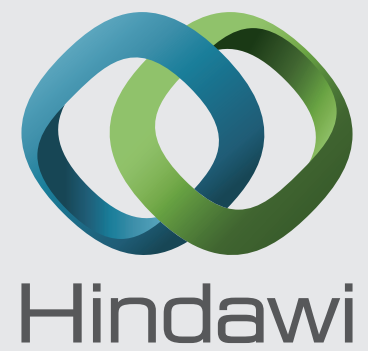

Submit your manuscripts at http://www.hindawi.com
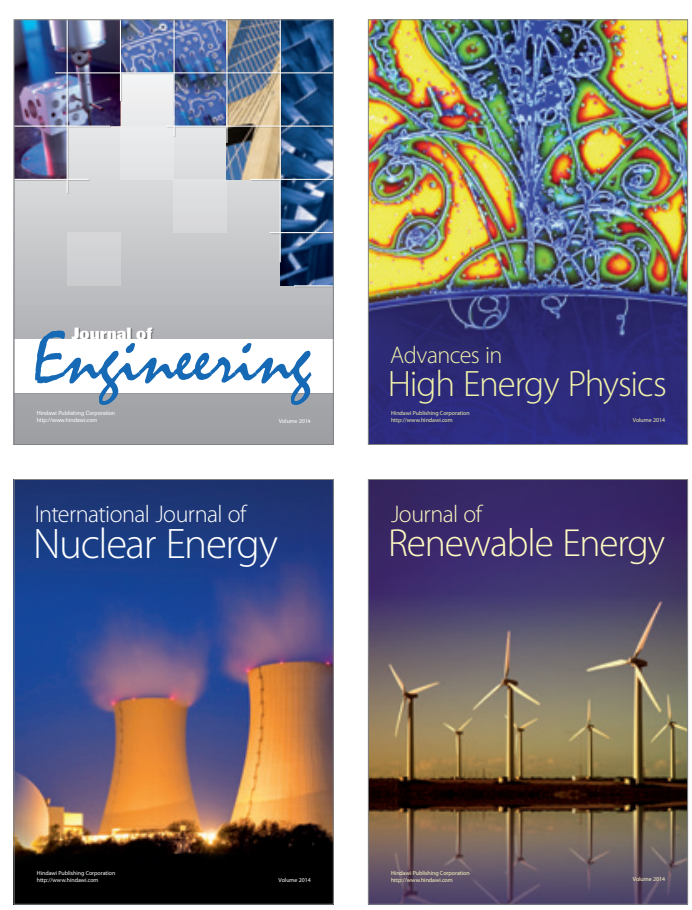

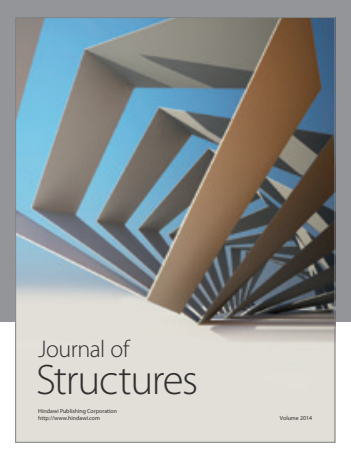

Rotating
Mechinery
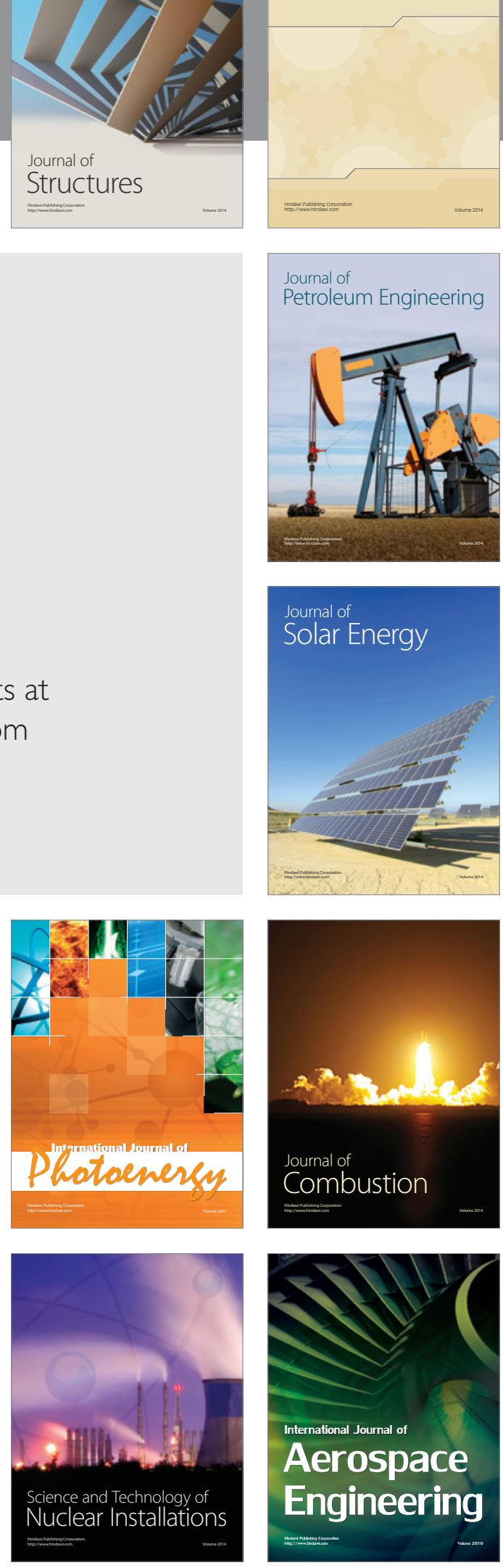